\title{
Marketing Public Relations Strategy in Developing Atourin's Brand Awareness (A Study Through Virtual Tour Events During COVID-19 Pandemic)
}

\author{
Veronica Veronica ${ }^{1}$ Lusia Savitri Setyo Utami ${ }^{*}$
}

\author{
${ }^{1}$ Faculty of Communication Science, Universitas Tarumanagara, West Jakarta, Jakarta 11440, Indonesia \\ ${ }^{*}$ Corresponding author. Email: lusias@fikom.untar.ac.id
}

\begin{abstract}
Atourin is a technology Start-Up company engaged in the tourism sector. As a Start-Up company, they need to increase public brand awareness of Atourin. One of the events that Atourin is doing during the pandemic is a virtual tour. The purpose of this study was to explain Atourin's Marketing Public Relations strategy and the efforts made to overcome obstacles during the pandemic in developing brand awareness through virtual tours. This study uses several supporting concepts, namely Public Relations, Marketing Public Relations, and brand awareness. The author uses a qualitative approach and a case study method. Data from the research results were obtained through observation, interviews with four informants, documentation, and literature. The results showed that the virtual tour had a significant impact on Atourin's brand awareness. Public Relations Marketing Strategies and strategy manifestations that are mostly carried out by publication through online media and social media have made Atourin better known by the government and some people. The obstacles that Atourin got in implementing its strategy were the lack of public awareness of the virtual tour and Atourin, along with the reduced publicity from online media over time to Atourin's virtual tour. The COVID19 pandemic is not an obstacle for Atourin in carrying out a virtual tour. Atourin used this situation as an opportunity to provide innovation for tourism activities in Indonesia.
\end{abstract}

\section{Keywords: Public relations, marketing public relations, brand awareness, virtual tour}

\section{INTRODUCTION}

Amid intense competition in the community to obtain and improve career opportunities, persuasive communication, dialogue, and tactical techniques are increasingly needed. Every company also needs techniques and excellent communication skills to communicate its vision and mission to its stakeholders. Techniques and abilities supported by effective communication strategies are very influential in determining individuals' and companies' success and failure to achieve something they want. Therefore, public relations in a company are significant for improving its image and building relationships with company stakeholders. Along with the times, Public Relations within a company or organization can expand its role in marketing products or services. In marketing communication, Public Relations are intended not only to enhance the company's image but also to communicate its product or image to the public.

Marketing Public Relations [1], is a planning and evaluation process that can stimulate sales and customers through communicating credible information and impressions that can connect companies, products to the needs and concerns of consumers/customers. Implementing an optimal Marketing Public Relations strategy can help the company effectively build consumer trust and promote its products or services. In carrying out this strategy, it is necessary first to confirm the goals the company wants to achieve, determine what tools and messages to convey, prepare a budget and schedule for implementing goals, and an evaluation to measure the effectiveness of the strategy taken [2]. With this strategy, the company is expected to create a positive impression on the public and build brand awareness of potential consumers of the company's products and services. Marketing Public Relations Strategy conducted by the company intended to allow the audience to recognize a particular brand and reach the Top of Mind or the highest level of brand awareness in prospective consumers' minds. Atourin is a technology start-up company engaged in the tourism sector. As a Start-Up company, they need to increase public brand awareness of Atourin. One of the programs or events currently being carried out by Atourin is a virtual tour. Virtual tours are intended for travelers who want to know in advance the recommended places from the destination they want to visit in the future, with a local guide as the speaker in the events.

The Indonesia situation with pandemic COVID-19 in 2020 has resulted in all face-to-face activities being suspended to prevent further spread of the virus. Many companies 
from various sectors suffered losses. One of the industries that have been the biggest hit by the pandemic is the tourism sector. With travel restrictions and calls for social distancing, the number of tourists has decreased in recent months. Based on data from the Ministry of Tourism and Creative Economy, tourist visits to Indonesia through all entrances in July 2020 decreased by $-89.12 \%$ compared to July 2019. As a company engaged in the tourism sector, this is a challenge for Atourin to innovate and think of the right strategy to raise the tourism sector during a pandemic and introduce and increase Atourin's brand awareness to the public through virtual tours.

This study was made to describe Atourin's Marketing Public Relations strategy to increase brand awareness during the pandemic through virtual tours and describe the efforts to overcome obstacles during the pandemic while implementing Marketing Public Relations strategies through virtual tours.

\subsection{Related Works}

Several studies on Marketing Public Relations activities increase brand awareness, which the authors take as a reference.

The first reference [3] is based on research in knowing the efforts to increase brand awareness of PT. Go-Jek Indonesia through Marketing Public Relations activities. This research used qualitative research method and Marketing Public Relations and brand awareness concept. The results showed that PT. Go-Jek Indonesia uses Public Relations tools through the P.E.N.C.I.L.S mix theory, according to Thomas L. Harris. The implementation of Go-Jek activities based on this concept is considered effective because it has succeeded in increasing Go-Jek brand awareness and creating a positive image in the eyes of its users.

The second reference [4] is based on research explaining Checo Cafe Resto's Marketing Public Relations Strategy. This research used qualitative research method and threeways strategy concept. The results showed that Checo Café Resto experienced a decline in sales and gained an image as an 'expensive café' during its rebranding. However, after implementing the three-way strategy, offering cooperation such as sponsorship, and increasing publicity through electronic media and social media, sales and positive image can rise in the post-rebranding phase.

The last reference [5] is based on research describing Marketing Communication in developing Partipost's brand awareness. This research used qualitative research method and marketing communication concept. The results showed that Partipost uses six marketing elements: advertising, sales promotion, direct marketing, internet marketing, events and experiences, and word of mouth. Partipost also makes use of marketing campaigns to increase brand awareness.

\section{BACKGROUND}

\subsection{Communication and Marketing}

According to Gerald R. Miller [6], communication occurs when a source delivers messages to the recipient with a conscious intention to influence the recipient's behavior. Communication in marketing is carried out by companies as a way to inform, persuade, and remind consumers directly or indirectly about the products sold by the company. communication with marketing has a close relationship [7]. Communication in marketing is complex and not as simple as communicating with family. Through proper communication strategies and a careful planning process, the company message can be conveyed. In this report, the message is to increase Atourin's brand awareness through virtual tours.

\subsection{Public Relations}

Denny Griswold [8] states that Public Relations is a function of management that assesses public attitudes. It shows the policies and procedures of an individual or institution based on public plans and work plans to understand and be well received by the public or audience. Bertrand R. Canfield, in his book entitled "Public Relations, Principles, and Problems," states that there are three functions of Public Relations. Based on Bertrand's statement, those functions serve the public's interest, maintain good communication, and stress good morals and manners [8]. The purpose of the Public Relations activities is basically to form a positive or pleasant public opinion regarding the activities carried out by the company. In carrying out the functions and objectives of Public Relations, practitioners must have a priority scale to be achieved in the long or short term first.

\subsection{Marketing Public Relations}

Thomas L. Harris [1] stated that Marketing Public Relations is a planning and evaluation process that can stimulate sales and customers through communicating credible information and impressions that can connect companies and products with consumers' needs and interests.

There are seven main tools in Marketing Public Relations, such as publications, events, news, sponsorships, speeches, public service activities, and identity media [2]. There are also also three strategy tactics (three-ways strategy) to realize Marketing Public Relations activities such as pull, push, and pass strategy [1]. Pull Strategy is carried out as a Public Relations effort to attract the public's attention in various ways to achieve company goals and increase sales of products or services. Push Strategy is carried out to increase the number of product/service purchases to increase sales numbers. Pass Strategy is carried out to influence public opinion through various activities, community activities, social responsibility, and concern 
for issues related to the company's conditions and environment.

\subsubsection{Marketing public relations strategy}

Several steps are defined as a Marketing Public Relations strategy [2]. This strategy is a plan from company management formulated to advance and/or develop a planned company for the short and long term. Atourin can carry out this strategy to increase brand awareness in the eyes of the public. Public Relations Marketing Strategies include establishing objectives, choosing messages and vehicles, implementing the plan, and evaluating it. Establishing objectives is the most important part of determining the strategy by setting the company's goals, choosing messages and vehicles associated with the various decisions taken to the message sent, and conveying the message to the public key, content, sound, and style of the message. Next, implementation of the plan is used to develop a budget and a schedule prepared to implement a predetermined program. Evaluative research is the final step taken to develop specific methods for managing the effectiveness of the strategies that have been taken.

\subsection{Brand Awareness}

Branding is a name, term, sign, symbol, or design and a combination of all aiming to identify goods or services to differentiate them from others [2]. In this research, PT. Atourin Teknologi Nusantara is a company engaged in the tourism sector with 'Atourin' as its brand name. Brand awareness levels are divided into several groups such as Top of Mind, Brand Recall, Brand Recognition, and Unaware of Brand. Atourin, a Start-Up company, strives to reach the highest level in the brand awareness stage, to prove that Atourin is one of the brands known and sought after by travelers when they want to participate in virtual tour events.

\section{METHODS}

The approach used in this research is qualitative research. Qualitative research is data collection in a natural setting to interpret the phenomena that occur with the researcher as a key instrument, data sampling is done purposively and snowball, collection techniques are triangulation (combined), data analysis inductive, and the results of the study emphasize the meaning rather than generalization [9].

The research method used is the case study method. This method is a method whose strength lies in the ability to use various sources and or available evidence so that researchers can get answers to the problems under study [3].

In this study, the research subject was the Chief Financial and Partnership Officer Muchdlir Johar Zauhariy as the key informant, or familiarly called Johar. In carrying out the virtual tour, Johar is one of the individuals who play a role in setting the right strategy for Atourin's services. The author also conducted a brief interview with three followers of Atourin's Instagram account who were considered to know Atourin already and learned about the virtual tour event organized by Atourin. The object of this research is Atourin's Marketing Public Relations strategy in developing brand awareness during the pandemic through virtual tours. The author chose to observe an increase in brand awareness through virtual tours because virtual tours are among the most popular services from other services provided by Atourin. At the time of this report, Atourin had carried out virtual tours 140 times in 29 provinces in Indonesia.

The author uses data processing and analysis techniques based on Miles and Huberman [10] which consists of data reduction, data presentation, and conclusion drawing. The author uses triangulation techniques to test the validity of the resulting data. The triangulation technique used is source triangulation. Source triangulation is a triangulation technique by digging the truth from certain information through various data collection methods and sources. The author uses the source triangulation technique by comparing observations and interviews with informants with the concepts and/or theories that the authors get from literature studies.

\section{FINDINGS AND DISCUSSIONS}

\subsection{Observation Unit General Description}

Atourin Teknologi Nusantara, better known as Atourin, is a technology company in the tourism sector that provides one-stop-solution services to tourists, such as providing information on tourism objects throughout Indonesia, helping plans to various destinations in Indonesia, and certified travel guide booking services.

Atourin was founded in mid-2018 by Benarivo Triadi Putra and two of his friends. At first, Atourin was established to help tourists search for travel routes and sites with a drag and drop system focusing on technologybased. 2019 was Atourin's lowest point in company development because many colleagues resigned from Atourin. Rivo, who still has aspirations to build Atourin, finally meets Reza Permadi and Johar Zauhariy, who already have several experiences in the tourism sector and rearrange the Atourin concept to sell products that are not only focused on technology but can also sell something that is readily accepted by the public. Until the author conducted this research, Atourin was developed by three individuals who played a significant role in the process: Chief Executive Officer Benarivo Triadi Putra, Chief Operating Officer Reza Permadi, and Chief Financial Partnership Officer Johar Zauhariy, assisted by eleven unnamed staffs and role. 


\subsection{Findings}

\subsubsection{Atourin's public relations activities}

Johar revealed that before 2020, Atourin had no Public Relations activities. Public Relations activities have only been carried out since the COVID-19 pandemic hit Indonesia. Currently, Johar is in charge of every Public Relations activity, including making press releases for the company. This press release has been published in various online media, including Detik, Tempo, Kompas, Jakartapost, and Kumparan. Atourin's activities such as virtual tours, Atourin Talk, and Atourin Sharing are published on the @ atourin.official Instagram account. Not only uploading photos of Atourin's activities, but this Instagram account also provides some facts about the world of tourism. According to Johar, these activities are essential in developing Atourin's brand awareness. Publication on social media and online media and publishing press releases help raise awareness of the Atourin brand.

Atourin also has several campaigns that will be implemented over time. Johar said that there were four campaigns prepared by Atourin related to tourism, such as Travelers Power, We are Quality Tourism, a collaborative project with the Ministry of Tourism and Creative Economic in inviting all active people in the world of tourism to know their respective roles. Then, One Traveler One Tree, which is a joint project with one of Atourin's partners related to forest planting by planting one tree from every virtual tour ticket or tour package sold. Last, Stonger Beyond Pandemic is a special campaign for tourism activists carried out mutually by giving emotional support and providing facilitation assistance for tourism management.

\subsubsection{Atourin's virtual tours during pandemic}

In early 2020, Atourin not yet had the idea to launch a virtual tour so that sales of products at the beginning of the year are more inclined to travel plans and travel packages. Johar revealed that Atourin's team accidentally sparked the idea of going on a virtual tour. However, the virtual tour program was beneficial for Atourin because no company in the same sector conducted a virtual tour. This is also an opportunity for Johar to launch a press release about virtual tours to several online media such as Kompas, Detik, Kumparan, Tempo, and Jakartapost to get publications about virtual tours initiated by Atourin's team. After the press release was published, many parties were interested in finding out more about Atourin and the virtual tour. Johar stated that the parties were the government and private companies.

The author made observations on the virtual tour from July to August 2020 by becoming an intern at Atourin. The author participated in several virtual tours by Atourin, such as the Jakarta Anniversary virtual tour on 22 June 2020, the Labuan Bajo virtual tour on 18 July 2020, and the Tanjung Putting virtual tour on 19 July 2020. Based on the author's observations, about 10 to 30 people attended the three virtual tours depending on their being taken. The author observed that more participants participated in the Labuan Bajo destination's virtual tour from three destinations. In the interview, Johar stated that the number of virtual tour participants is not always consistent but depends on the destination of the virtual tour. Johar said that Labuan Bajo is one of the favorite destinations besides Sumba and Raja Ampat.

\subsubsection{Virtual tour's marketing public relation strategy}

In the virtual tour training on July 15, 2020, Reza Permadi, as Chief Operating Officer of Atourin, or familiarly called Reza, revealed the idea of forming a virtual tour at the event. Reza stated that a virtual tour concept was obtained when he saw an article about a museum in Europe that held a virtual tour of the museum.

At first, Atourin's team conducted research or surveys to get feedback about the virtual tour through Atourin's social media. The target set by Atourin is the general public. According to Reza in the Virtual Tour Training event on July 16, 2020, virtual tours are more followed by individuals aged 17 to 30 who want to travel independently or known as backpackers, followed by individuals aged 41 to 50 years based on the most survey data. The virtual tour price set by Atourin is also based on the results carried out by checking the virtual tour market through a survey until a price range of $\mathrm{Rp} 30,000$ to Rp50,000 is obtained for one virtual tour event. Reza also revealed that attractive event poster design is also one of the marketing techniques in attracting consumers through visual posters. Based on the survey conducted, Reza stated that consumers are interested in joining the virtual tour because there are photos of tourist sites and the name of the guide on the poster. After researching and finding that there was a market opportunity for this activity, Atourin launched his first virtual tour with Natuna destinations but used a tour guide. Reza stated that $90 \%$ of virtual tour participants were satisfied with the virtual tour held by Atourin and created new clients such as companies that asked Atourin to hold virtual tours privately for their company. The author also received positive impressions from two supporting informants.

Reza also revealed that the virtual tour activity is not aimed at shutting down the real-time travel industry, but virtual tours are held to research in advance of the destinations they are going to. Johar stated the same thing as Reza in the interview.

\subsubsection{Obstacles and their relations to pandemic}

In the interview, Johar said that the obstacles or obstacles that were the main problem came from the virtual tour, generally from the internet connection. Apart from the internet connection, tour guides' ability to present virtual tours is also a problem because Atourin tries to provide the best competent guides to guide virtual tour participants. 
Johar revealed that not all guides have the ability to tell good stories to present the locations.

From a market point of view, Johar revealed that the audience's expectations of virtual tours differ. Many expect that the virtual tour will be carried out through live reporting and are considered unattractive because there are no traditional or regional dances. Many people don't know about the virtual tour. In terms of Atourin's team, Johar stated that the limited team members made work difficult. With few team members, each individual in Atourin is expected to help each other carry out one task and another. Johar said that Indonesia, currently experiencing a pandemic due to COVID-19, has not brought harm to Atourin. According to him, this pandemic Atourin team up with the idea of carrying out the virtual tour also develop and increasing brand awareness of Atourin to various stakeholders such as governments, private companies, travel activists, and even tourists. Publication on Atourin, which has begun to decrease, has also become one of the obstacles. Atourin has innovated by holding supporting events such as Atourin Talk and Atourin Sharing.

\subsection{Analysis and Discussions}

\subsubsection{Public relations as atourin's marketing support}

The author summarizes that Atourin's Public Relations activities aim to foster a positive image to the community. Besides that, to develop synergy between Atourin's marketing activities and Public Relations activities. Such as by sending press releases to online media to get publications and communicate virtual tours to the community and other stakeholders from Atourin, such as the Ministry of Tourism and Creative Economic and BAKTI and private companies interested in the virtual tour introduced by Atourin. Based on the author's observations on Atourin's Instagram account named @ atourin.official, Atourin answers almost all questions in the comments column and giving responses in the upload. The author also found many articles about Atourin's virtual tour on online media such as Kompas, Detik, Kumparan, and Jakartapost.

\subsubsection{Atourin's marketing public relations strategy and activities}

\subsubsection{Atourin's marketing public relations main $\underline{\text { tools }}$}

There are seven main marketing public relations tools: publications, events, news, sponsorships, speeches, public service activities, and media identity [2].

Atourin's Marketing Public Relations activities are carried out by publishing to Instagram social media and sending press releases and news about virtual tours and virtual tour training, also getting publications to various online media and Atourin's stakeholders such as the Ministry of Tourism and Creative Economic. Atourin also carried out multiple events with the main focus on virtual tours during the pandemic, which according to Johar, has reached 140 virtual tours with 29 provinces in Indonesia, followed by complementary events such as Atourin Talk has been held seven times and Atourin Sharing about three times. Atourin also carried out a social campaign by implementing \#StrongerBeyondPandemic and three other campaigns that will be carried out in the future. Besides, Atourin also uses a media identity that focuses on purple, which draws the distinctive color of the Atourin company.

\subsubsection{Atourin's marketing public relations strategy}

Based on the author's interviews and observations, Atourin's strategies are closed to what Kotler and Keller stated.

\subsection{Define goals and ideas}

This step is the first step Atourin with a reason to survive during a pandemic. The number of business sectors experiencing a crisis during the pandemic, including the tourism sector, made Atourin look for ideas to create innovations in its activities, namely by virtual tours. Although Johar said that the concept of a virtual tour was just a fad, Atourin finally focused on doing a virtual tour to introduce virtual tours as a substitute for temporary tourism activities during a pandemic and a reference for tourists who would later visit the desired tourist destination.

\subsection{Doing research and determining the means}

Various surveys and research conducted by Atourin, including a demographic study of virtual tour participants, also survey the price range for virtual tours. After completing several research and surveys, Atourin conducted a virtual tour. Virtual tours are carried out online through the Zoom application and guided by a tour guide in collaboration with Atourin. Based on the author's observations, Atourin will upload a poster about the virtual tour on his Instagram account within five to one week before the event is held. If the virtual tour event collaborates with Atourin's stakeholders, the partner will also upload Atourin's virtual tour posters on their social media accounts.

\subsection{Implementation}

After doing some research or surveys and determining what the virtual tour means, Atourin then realized the virtual tour activities. Virtual tours are carried out by Atourin online through Zoom and are carried out by showing routes and photos of destination tourist destinations in the virtual tour. After doing the virtual tour, Atourin will send a press release to online media, hoping to publish the virtual tour on their site. 


\subsection{Evaluation}

After carrying out the virtual tour, the Atourin team provided a form to fill in impressions and messages to get participant feedback on the virtual tour. Based on the author's interviews with the supporting informants, the three informants said they were satisfied with the virtual tour that Atourin held. Reza also revealed that $90 \%$ of virtual tour participants were pleased with the virtual tour conducted by Atourin.

Johar explained that not all participants have the same expectations of virtual tours because some expect the virtual tour to be carried out with live reports, filled with regional dances, etc. Johar stated that several virtual tours had been carried out with live reports after a lot of feedback suggested that the virtual tour should be done in a live report.

\subsubsection{Marketing public relations tactics through virtual tours}

There are three activities can be carried out in realizing Marketing Public Relations, namely through three ways strategy [1]. As a manifestation of Atourin's Marketing Public Relations strategy activities through virtual tours, the authors summarize that Atourin carries out the following actions.

Atourin uses his Instagram account to publish information about the virtual tour and re-upload the Instastory uploaded by participants regarding the virtual tour. Atourin, in one of the uploads on his Instagram account, also stated that several virtual tour events could be watched for free via Atourin's Youtube account. This is considered to attract the audience's attention and give the audience an idea of the virtual tour.

Reza revealed that Atourin provided virtual tour information by uploading interesting posters on Instagram to encourage sales. Based on the research conducted, many participants were interested in joining the virtual tour because they saw an attractive poster design. Johar also sends press releases to online media, hoping that the public will know about the virtual tour and drive sales and increase brand awareness of Atourin. Atourin also organizes virtual tour support events such as Atourin Talk and Atourin Sharing.

Based on the interviews the authors conducted with informants, the behavior of word of mouth was carried out by one of the informants by introducing virtual tours to friends and family, which indirectly made some parties know about Atourin and was expected to encourage sales of virtual tours.

Atourin carries out the pass strategy by helping tour guides who do not have adequate equipment and equipment to conduct virtual tours through borrowing Atourin's facilities such as company Zoom links and making tourist destination routes. Atourin also carried out a campaign related to tourism, namely Stronger Beyond Pandemic, as a form of Atourin's concern to emotionally strengthen each other in the tourism sector to fight and survive during the pandemic. Atourin is also working with several government parties to conduct virtual tour training for tour guides and the East Kalimantan Tourism Office to introduce East Kalimantan's nature and culture.

The author summarizes that the pull strategy activities focus on publications and push strategy activities to focus on the media, events, and publications. In contrast, the pass strategy activities focus on public service activities and government relations. The author also summarizes that in realizing Atourin's Marketing Public Relations strategy, the activities carried out by Atourin are more focused on publications that aim to increase public awareness of virtual tour activities in Indonesia while developing Atourin's brand awareness in the eyes of the public.

\subsubsection{The obstacles and solutions}

\subsection{Lack of awareness about virtual tours}

There are still many people who don't know about virtual tours. Johar also revealed that many companies do not know about Atourin and the virtual tour. In dealing with this, Johar revealed two ways. To introduce a virtual tour to a company is done by sending a company profile and virtual tour proposal to the company. This is considered successful by Johar because these methods have led several private companies to use Atourin's services to create virtual private tours for corporate purposes and invite government parties to cooperate in introducing virtual tours to the Indonesian people.

\subsection{Reduced publicity in online media}

Johar thinks that even though virtual tours are one of Atourin's services that consumers are interested in, the publication of this event in online media is decreasing. Atourin has innovated by launching various new events such as Atourin Talk and Atourin Sharing as a distraction and complement to the virtual tour events that are the focus for Atourin until the study was conducted.

\subsubsection{Influence on atourin's brand awareness}

In the interview regarding brand awareness, Johar stated that Atourin is one of the Tops of Minds for the government in the tourism sector, especially in virtual tours.

The author found that on the Jakartapost website, one of the articles entitled 'Seven Virtual tour Platforms to Visit During the Pandemic' in May 2020 wrote Atourin's name as one of the platforms that can be visited by the public when looking for a virtual tour during a pandemic. Based on this, for some online media, Atourin is already at the Brand Recognition stage.

Based on the author's observations through Atourin's Instagram account, Atourin has a following of 2,601 users. The author observed that the number of followers of Atourin's Instagram account increased by around 1300 
users compared to July 2020, which was only around 1300 Instagram users.

The author summarizes that many parties have put Atourin in the Top of Mind position for virtual tours, such as private companies, government, and virtual tour participants. Still, not all parties consider Atourin to be Top of Mind. For some parties, Atourin has reached the Brand Recognition stage, and when the party is asked about the virtual tour, Atourin will be at the Brand Recall stage from Atourin's Instagram account followers. The author also finds audiences who don't know about Atourin and the virtual tour or are Unaware of the Brand stage. Johar also stated that at the end of 2020, Atourin would claim to be one of the pioneers or leading images for virtual tours in Indonesia.

Overall, the authors summarize that in developing Atourin's brand awareness, the virtual tour becomes a significant event in raising Atourin's brand awareness in the public's eyes. The Marketing Public Relations strategy, which is realized through publications, media, events, and government relations, increases public awareness of Atourin. Atourin becomes one of the reliable platforms for virtual tours, according to the online news site Jakartapost. In implementing this strategy, there are obstacles such as a lack of awareness of Atourin and virtual tours. Atourin overcomes this by sending a company profile and virtual tour proposal to the parties who will cooperate to get to know Atourin and the virtual tour better. The reduced publicity in online media has also encouraged Atourin to create other events that support virtual tour activities such as Atourin Talk and Atourin Sharing.

The existence of the COVID-19 pandemic in 2020 does not impact the implementation of the Marketing Public Relations strategy or hinder the course of the virtual tour. Based on the interview results, the authors summarize that the pandemic situation was used as an opportunity by Atourin to introduce innovations in Indonesia's tourism activities through the provision of virtual tours. Based on the author's observations, Atourin is not the only platform that provides virtual tour services, and there are still many people who don't know about Atourin. However, Atourin is one of the Tops of Minds for several government parties, private companies, and virtual tour enthusiasts. In that, Atourin is a company that has become one of the pioneers or leading images in introducing virtual tours in Indonesia and has been active in raising virtual tours since the beginning of the pandemic.

\section{CONCLUSIONS}

Marketing Public Relations strategy carried out by Atourin in developing brand awareness through virtual tours was carried out by determining goals and ideas, conducting research and selecting facilities, implementing and evaluating events to help increase Atourin's brand awareness, especially during the pandemic in 2020. Atourin's Marketing Public Relations Activities activities are dominated by publications and events distributed through Atourin's social media and its stakeholders and online media. Even though still not widely recognized at the beginning of 2020, Atourin now one of the start-ups in the tourism sector that some audiences recognize. Besides, Top of Mind for the government as one of the platforms that can be searched for virtual tours and tourism. The COVID-19 pandemic is not an obstacle for Atourin in implementing the Marketing Public Relations strategy to introduce virtual tours and increase Atourin's brand awareness.

Based on the report results, the authors were unsuccessful in obtaining data about the results or the percentage of numbers that indicated that the virtual tour was successful in developing Atourin's brand awareness. The author hopes that further research will be made using a quantitative approach to calculate the percentage of the virtual tour's success in increasing Atourin's brand awareness in the eyes of the public.

\section{ACKNOWLEDGMENT}

The author gives thanks to God Almighty for the blessings and graces given to the author. The author would like to thank parents and friends who always provide support. The author is grateful to the adviser and Faculty of Communication Sciences of Tarumanagara University for their knowledge and guidance. The author also thanks Atourin and all the informants who provided the necessary information for the study.

\section{REFERENCES}

[1] R. Ruslan, Manajemen Public Relations dan Media Komunikasi, PT Raja Grafindo Persada, 2010.

[2] P. Kotler, K. Keller, Manajemen Pemasaran, Erlangga, 2013.

[3] U. Wahid, A.E. Puspita, Upaya Peningkatan Brand Awareness PT. Go-Jek Indonesia Melalui Aktivitas Marketing Public Relations, Jurnal Komunikasi, 9(1), pp. 31-43. DOI: http://dx.doi.org/10.24912/jk.v9i1.265

[4] S.A. Rahmawati, Y. Setianti, S. Lukman, Strategi Marketing Public Relations Checo Cafe Resto, Jurnal KOMUNIKATIF, $8(1)$, pp. 1-22. DOI: https://doi.org/10.33508/jk.v8i1.1981

[5] A. Belinda, R. Loisa, Komunikasi Pemasaran dalam membangun brand awareness (studi kasus Partipost), Jurnal Prologia, 3(1), pp. 9-16. DOI: http://dx.doi.org/10.24912/pr.v3i1.6112 
[6] A.S. Rustan, N. Hakki, Pengantar Ilmu Komunikasi, Deepublish, 2017.

[7] A. Firmansyah, Komunikasi Pemasaran, Qiara Media, 2020.

[8] Danandjaja, Peran Humas dalam Perusahaan, Graha Ilmu, 2011.

[9] A. Anggito, J. Setiawan, Metode Penelitian Kualitatif, CV Jejak Publisher, 2018.

[10] Sugiyono, Metode Penelitian Kuantitatif, Kualitatif, dan R\&D, Alfabeta, 2013. 